Article

\title{
Development of Operating Method of Multi-Geothermal Heat Pump Systems Using Variable Water Flow Rate Control and a COP Prediction Model Based on ANN
}

\author{
Ji-Hyun Shin ${ }^{1}$, Yong-In Kim ${ }^{2}$ and Young-Hum $\mathrm{Cho}^{3, *}$ \\ 1 Department of Architectural Engineering, Graduate School of Yeungnam University, 280 Daehak-Ro, \\ Gyeongsan, Gyeongbuk 38541, Korea; sjh1010@ynu.ac.kr \\ 2 NOW Consulting Engineers co. LTD, Seoul 05073, Korea; nowmec@chol.com \\ 3 School of Architecture, Yeungnam University, 280 Daehak-Ro, Gyeongsan, Gyeongbuk 38541, Korea \\ * Correspondence: yhcho@ynu.ac.kr; Tel./Fax: +82-53-810-3081
}

Received: 11 September 2019; Accepted: 9 October 2019; Published: 15 October 2019

\begin{abstract}
As the global energy trend continues, the importance of energy savings and efficient use is being emphasized, and the installation and operation of geothermal heat pump systems is increasing. In many buildings, where an actual geothermal heat pump system has been installed, problems of efficiency deterioration occur frequently because of the inefficient operation after installation of the heat pump system. The purpose of this study was to develop and verify the operating method for energy saving and performance improvement of multiple geothermal systems. A coefficient of performance (COP) prediction model using an artificial neural network for real-time COP predictions was developed. The operating method of a multi-geothermal heat pump system using a variable water flow rate control method and COP prediction model was developed. The geothermal heat pump system operates sequentially depending on the water flow rate of the circulation pump. The COP prediction model enabled real-time performance prediction during system operation. The circulation water flow rate was reduced by up to $29 \%$ compared to the existing operating method. Approximately $23 \%$ of the energy was saved. The COP system, including the consumption power of the circulation pump, was improved.
\end{abstract}

Keywords: geothermal heat pump system; variable water flow rate control; operating method; COP (coefficient of performance) prediction; ANN (artificial neural network)

\section{Introduction}

With the global increase in energy consumption, there is a continuing social interest in energy savings and efficient use in the building sector. For long-term energy savings, renewable energy technologies that help reduce energy costs, stabilize supplies, and reduce greenhouse gas emissions have attracted increasing attention. Among the new and renewable energies, the installation and utilization of geothermal heat pump systems are increasing. These systems can operate efficiently throughout the year because the ground temperature is warmer than the ground surface temperature in the winter and cooler in summer, and they have excellent cooling and heating performance. Because of the initial high installation cost of the entire system, a geothermal heat pump system needs to be designed properly to reduce the installation cost and maintain stable performance. After installation, it is essential to save energy, secure system performance, and reduce the operating cost through the efficient operation of geothermal heat pump systems. 
The inefficient operation of a geothermal system is an operation method utilizing the constant flow control method of a circulation pump. In general, while operating under a partial load, the circulation pump supplies a constant flow rate and wastes circulation pump energy. The variable flow control of the geothermal circulation pump reduces the pump power consumption under a partial load and improves the overall system coefficient of performance (COP) considering the pump power. Several studies related to varying flow rates in geothermal systems have been reported. Granryd analyzed the optimal flow rate in the secondary loop [1]. Song proposed a method to control the flow rate of a geothermal system and confirmed the performance improvement through empirical research on the heating operation [2]. Montagud developed an experimental in situ optimization methodology for the water circulation pump frequency of ground source heat pump systems [3]. This paper proposes an operating method of a multi-heat pump system using the variable flow rate control of a geothermal circulation pump. The operating method of a multi-heat pump using variable flow control rather than the operation of a single heat pump enables not only the energy savings of circulation pump, but also an improvement in the overall system performance. In addition, various studies related to geothermal performance are conducted [4-11].

In geothermal heat pump systems, the COP is an important indicator of efficient operation. To determine the COP, several variables, such as temperature, flow rate, and power, are required. In the field, it is difficult to obtain multiple variables in real time because of the lack of equipment to measure each variable or the lack of a monitoring system. It is necessary to predict the COP through variables that can be easily monitored. In this paper, an artificial neural network (ANN), which is used to predict specific values for system control and fault diagnosis, is used for COP prediction. In the HVAC (Heating, Ventilation and Air Conditioning) field, ANN is used to predict for building loads, temperature and humidity to reduce energy consumption, predicting energy consumption in buildings, and controlling thermal [12-15]. An artificial neural network (ANN) is a computational model that adopts neural transmission structure and learning methods. Because of the advantages of learning ability and nonlinear approximation, ANNs can be applied to various predictions. In relation to the performance prediction of geothermal systems, studies were conducted on how to predict performance using different models or how to improve the accuracy of the prediction model $[16,17]$. However, no research has applied the performance prediction model to multi-geothermal system operation. This study aims to develop a performance prediction model using ANNs for real-time performance verification during geothermal system operation. The development of a COP prediction model using an ANN enables a real-time performance prediction during system operation. Developed performance prediction models are applied to geothermal system operating algorithms to identify various problems such as performance degradation.

The purpose of this study is to develop a COP prediction model using ANN and to develop a multi-geothermal heat pump system using the variable flow rate control of a circulating pump. The COP prediction model is applied to the geothermal system operation method to check real-time performance, and to enable efficient operation of the geothermal system.

\section{Geothermal Heat Pump System Information of the Target Building}

\section{Building Information}

The target building was nine floors above ground and two floors underground; the total floor and air conditioning areas were $49,667 \mathrm{~m}^{2}$ and $33,744 \mathrm{~m}^{2}$, respectively. Table 1 provides an overview of the target building and Figure 1 provides a façade of the target building. 
Table 1. Target building information.

\begin{tabular}{ccc}
\hline \multicolumn{2}{c}{ Classification } & Contents \\
\hline & Location & Daegu, Korea \\
Buildings & Building stories & 9 floors above ground, 2 floors underground \\
& Building purpose & Mixed-use building \\
& Gross floor area & $49,667 \mathrm{~m}^{2}$ \\
& Building area & $7653 \mathrm{~m}^{2}$ \\
\hline
\end{tabular}

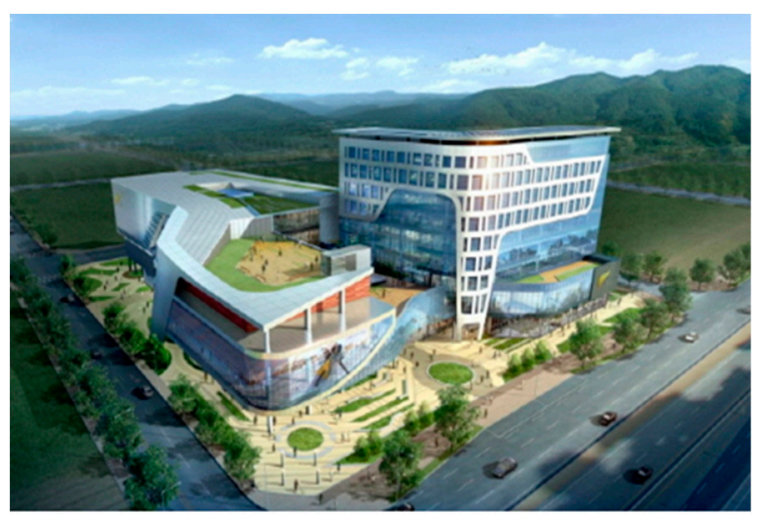

Figure 1. Target building facade.

The target building uses a boiler, an ice storage system, and a geothermal heat pump system. The geothermal heat pump system of the target building is separated from the other heat source systems, accounting for approximately $26 \%$ of the total heating and cooling. Table 2 lists the specifications of the heat pump and circulation pump.

Table 2. Geothermal heat pump system information.

\begin{tabular}{|c|c|c|c|}
\hline \multicolumn{2}{|c|}{ Classification } & \multicolumn{2}{|c|}{ Contents } \\
\hline \multirow{6}{*}{ Geothermal heat pump } & Quantity & \multicolumn{2}{|c|}{7} \\
\hline & Capacity (kW) & $\begin{array}{c}\text { Cooling } \\
170\end{array}$ & $\begin{array}{c}\text { Heating } \\
156\end{array}$ \\
\hline & Power consumption (kW) & 46.5 & 45.6 \\
\hline & Entering source temperature $\left({ }^{\circ} \mathrm{C}\right)$ & 25 & 5 \\
\hline & Supplied temperature $\left({ }^{\circ} \mathrm{C}\right)$ & 12 & 40 \\
\hline & Flow Rate $\left(\mathrm{m}^{3} / \mathrm{h}\right)$ & 36 & 36 \\
\hline \multirow{4}{*}{ Circulation pump } & Quantity & \multicolumn{2}{|c|}{8} \\
\hline & Flow rate $\left(\mathrm{m}^{3} / \mathrm{h}\right)$ & \multicolumn{2}{|c|}{54} \\
\hline & Head $(\mathrm{m})$ & \multicolumn{2}{|c|}{35} \\
\hline & Power consumption $(\mathrm{kW})$ & \multicolumn{2}{|c|}{7.5} \\
\hline
\end{tabular}

A computer monitored and operated the geothermal system of the target building, and the operating number control was performed based on the hot and cold water supply temperature.

\section{ANN Models for COP Prediction of Geothermal Heat Pump System}

\subsection{ANN}

ANN theory, developed by Warren McCulloch and Walter Pitts, is a computational model that introduces human neurotransmission structures and learning methods. The ANN model is a black box model, whose internal processing method is unknown. The ANN model analyzes the relationship between the input and output data based on a set of training data. An ANN consists of an input layer, 
hidden layer, and output layer. The input layer accepts input from outside the system and passes the data to the system. The hidden layer is an internal processing layer that carries the information and processes the input values to produce a result. The hidden layer is divided into a single hidden layer and multiple hidden layers. Each layer consists of nodes and calculates the output using the relationships between the variables and transfer functions. The last hidden layer exports information to the output layer. This process is a feed-forward process. Figure 2 illustrates the typical ANN model structure.

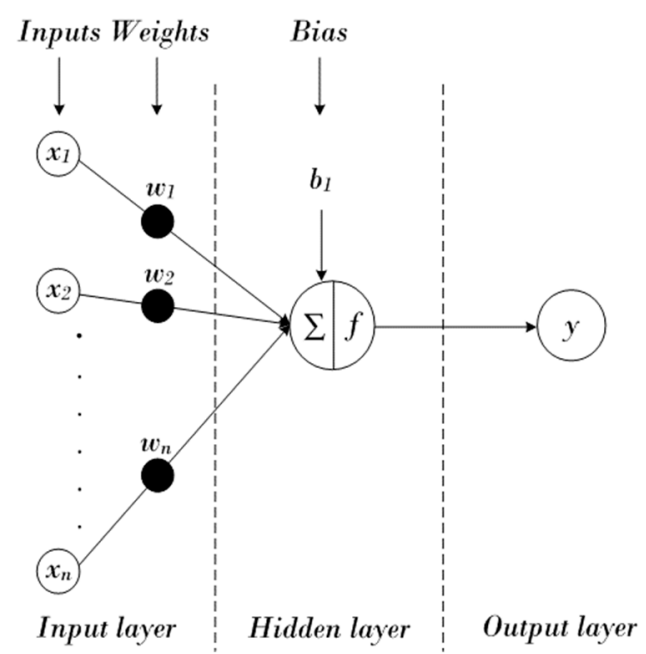

Figure 2. Artificial neural network model.

In the ANN, each node is weighted according to its importance. The output of the ANN according to the weight is given by Equation (1):

$$
\sum(x)=\sum_{i=1}^{n} w_{i} x_{i}+b_{i}
$$

On the other hand, if the output value calculated in the model differs from the actual result, the ANN goes through a back-propagation step to modify the relationship between the variables to make calculations that are more accurate. The algorithm that modifies the weights by reducing errors and reaching the optimal weights is expressed as follows:

$$
\Delta w=-\alpha \frac{\partial E}{\partial w}
$$

The modification of weight for the $(n+1)$ th pattern is expressed as follows:

$$
w(n+1)=w(n)+\Delta w=w(n)-\alpha \frac{\partial E}{\partial w}
$$

The ANN repeats the forward process of calculating the output and error, and the backward process of updating the weight with the error of the output. This process is repeated until the error is low enough. The processed information is converted to output signals through activation functions, such as the sigmoid function, threshold function, and hyperbolic tangent function. In this paper, the sigmoid function was used as the activation function. The activation function is given by Equation (4), as follows:

$$
f(x)=\frac{1}{1+e^{-\sum(x)}}
$$




\subsection{ANN Models for COP Prediction}

Real-time performance verification during operation is very important but difficult when using geothermal systems. For efficient system operation, a coefficient of performance prediction model was developed based on the data commonly measured in geothermal systems. In this study, four parameters $\left(T_{\text {source }, i}, T_{\text {source }, o}, T_{\text {load }, i}\right.$ and $\left.T_{\text {load }, o}\right)$ were used to predict the COP of the heat pump system based on the ANN. The training was conducted using 2000 data points. Of these, 1400 data points are used to develop the predictive model and 600 data points are used to verify the developed predictive model. The number of nodes in the hidden layer of the predictive model was selected as the number of minimized root-mean square (RMS) [1]. Table 3 presents the composition of the predictive model.

Table 3. Composition of the predictive model.

\begin{tabular}{ccc}
\hline & Classification & Contents \\
\hline Input layer & The number of neurons & 4 \\
\hline \multirow{2}{*}{ Hidden layer } & The number of nodes & 5 \\
& The number of neurons & 1 \\
\hline Output layer & The number of neurons & 1 \\
\hline \multicolumn{2}{c}{ Activation function } & Sigmoid \\
\hline
\end{tabular}

Figure 3 compares the COP predicted by the developed ANN model. Statistical methods, such as the absolute error (AE), relative error (RE), root-mean square (RMS), and coefficient of determination $\left(\mathrm{R}^{2}\right)$, were used to validate the developed ANN model. Smaller RMS and error values indicate a better ANN model, in which the $\mathrm{R}^{2}$ value is close to one. The statistical values are expressed as Equations (5)-(8). Table 4 lists the statistical values.

$$
\begin{gathered}
A E=x_{\text {actual }}-x_{\text {calculate }} \\
R E=\frac{x_{\text {actual }}-x_{\text {calculate }}}{x_{\text {actual }}} \\
R M S=\sqrt{\frac{\sum_{m=1}^{n}\left(x_{\text {actual }}-x_{\text {calculate }}\right)^{2}}{n}} \\
R^{2}=1-\frac{\sum_{m=1}^{n}\left(x_{\text {actual }}-x_{\text {calculate }}\right)^{2}}{\sum_{m=1}^{n}\left(x_{\text {calculate }}\right)^{2}}
\end{gathered}
$$

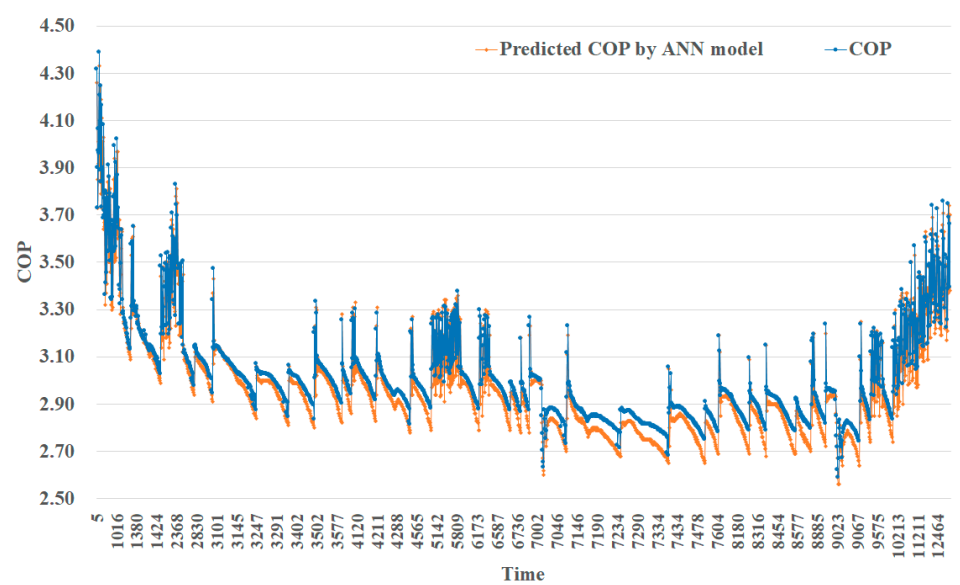

Figure 3. Artificial neural network model comparison of the coefficient of performance (COP) and predicted COP by the artificial neural network (ANN). 
Table 4. Statistical values for the predictive model. RMS = root-mean square; $\mathrm{R}^{2}=$ coefficient of determination; $\mathrm{AE}=$ absolute error; $\mathrm{RE}=$ relative error.

\begin{tabular}{ccccc}
\hline \multirow{2}{*}{ Predictive Model } & RMS & $\mathrm{R}^{2}$ & AE & RE \\
\cline { 2 - 5 } & 0.087579 & 0.989475 & -0.14 to 0.11 & -0.06 to 0.03 \\
\hline
\end{tabular}

The relative error of the ANN model was less than $10 \%$, and the absolute error and RMS values were small. In addition, $R^{2} \approx 1$, and thus the developed prediction model was valid and suitable for operational algorithms.

\section{Development of the Operating Method of a Multi-Geothermal Heat Pump System}

\subsection{Impact of a Variable Flow Rate on the System Performance}

To develop an operating method of a multi-geothermal heat pump system using the variable water flow rate control method, it is essential to check how a change in flow rate affects the energy consumption and performance of the system. A higher circulating flow rate in the geothermal system results in a smaller temperature difference. This reduces the work of the compressor and improves the performance of the heat pump. In terms of the overall system, a higher circulation flow rate results in more energy use in the circulation pump. Figure 4 shows the energy consumption of the pump according to the change in flow rate. In general, the energy consumption of the pump increases in proportion to the cube of the flow rate. When operating at high flow rates, the overall system performance is reduced because of the influence of the circulation pump's energy consumption.

Figure 5 shows the heat pump performance and overall system performance according to the flow rate. As the flow rate increases, the performance of the heat pump increases, but when the flow rate exceeds a certain flow rate, the increase in energy consumption of the circulation pump is greater than the decrease in energy consumption of heat pump, and the system performance deteriorates. Therefore, to improve performance and save energy, an operating method of a multi-geothermal heat pump system using variable water flow rate control was developed.

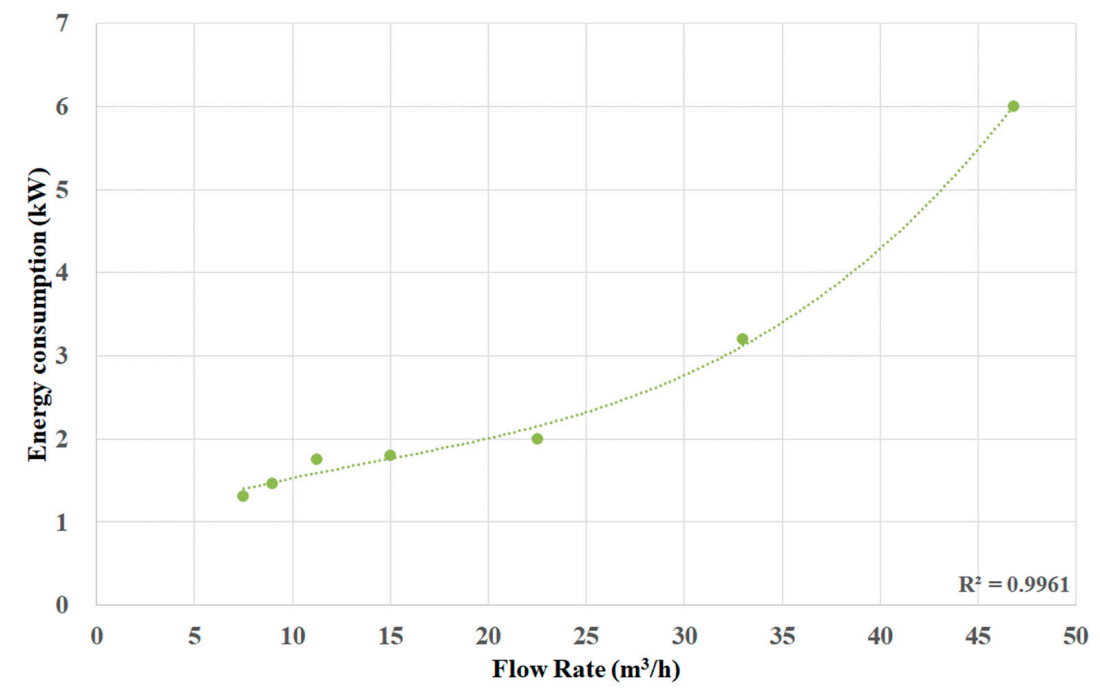

Figure 4. Relationship of flow rate and pump power. 


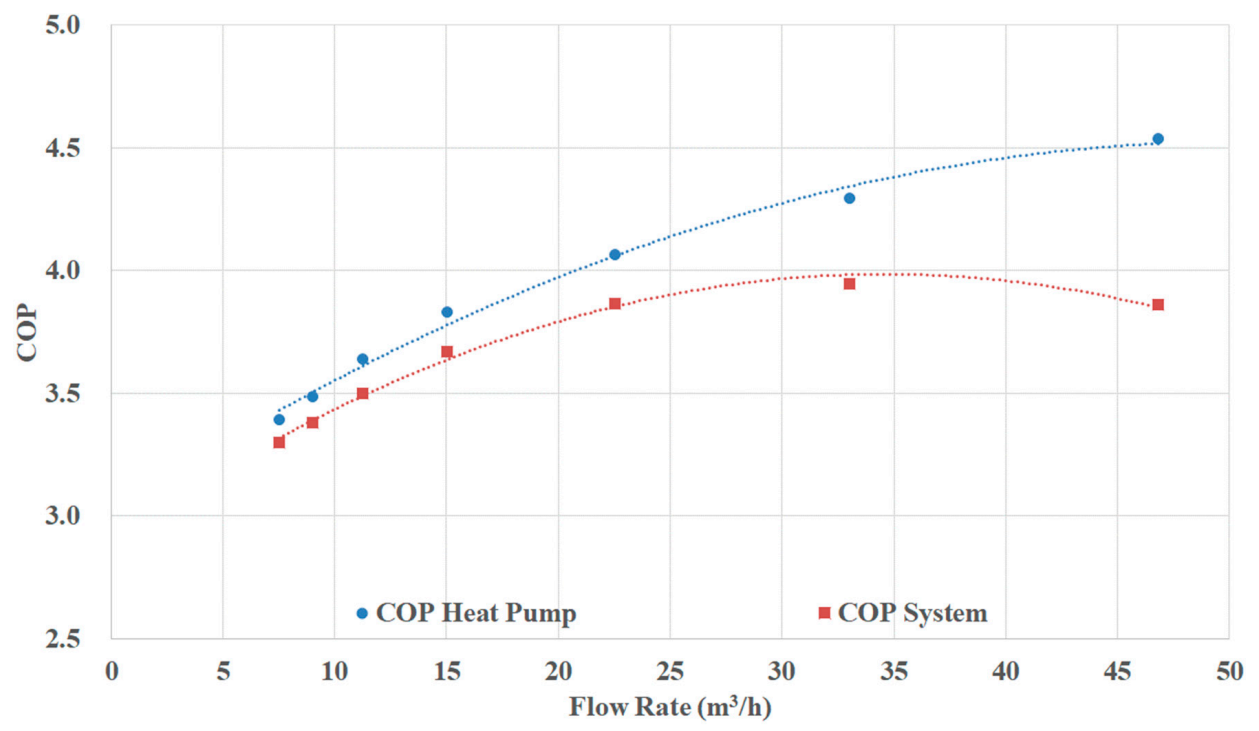

Figure 5. Relationship of flow rate and COP.

This paper proposes an operating method that operates multiple heat pumps efficiently using the underground circulation variable water flow rate control method, which can reduce energy consumption and improve the performance of the geothermal heat pump system. The general operating method of a geothermal heat pump system was compared with the proposed operating method.

\subsection{Operating Number Control Method of Multi-Geothermal Heat Pump System Using Constant Water Flow Rate Control Method}

Generally, the geothermal heat pump system uses the constant water flow rate control method of a circulation pump that supplies a constant water flow rate regardless of the change in load. The existing operation of a multi-geothermal heat pump system utilizes the operating number control according to the set temperature of the system using a constant water flow rate control method. Based on the cold and hot water set temperature, when the outlet temperature of cold water reaches the set upper limit, the system is operated, and the operation of the heat pump is stopped when the cold water outlet temperature reaches the set lower limit. Figure 6 shows the existing operation algorithm of the multi-geothermal heat pump system.

1. When the heat pump system is not operating

The geothermal heat pump system is operating when the cold water outlet temperature of the heat pump is higher than the set temperature $\left(T_{w}>T_{\text {set }}+d\right)$. The operation of the next heat pump system is determined depending on whether the cold water outlet temperature meets the set value. The current state is maintained when the cold water outlet temperature of the heat pump is lower than the set temperature $\left(T_{w}<T_{\text {set }}-d\right)$.

2. When the heat pump system is operating

If the cold water outlet temperature of the heat pump is lower than the set temperature $\left(T_{w}<\right.$ $\left.T_{\text {set }}-d\right)$, the operation of the heat pump is stopped. The heat pump is also operated to fix the set temperature when the temperature of the cold water outlet of the heat pump is higher than the set temperature $\left(T_{w}>T_{\text {set }}+d\right)$, and the operation of heat pump system is stopped when the cold water outlet temperature of the heat pump becomes lower than the set temperature. 


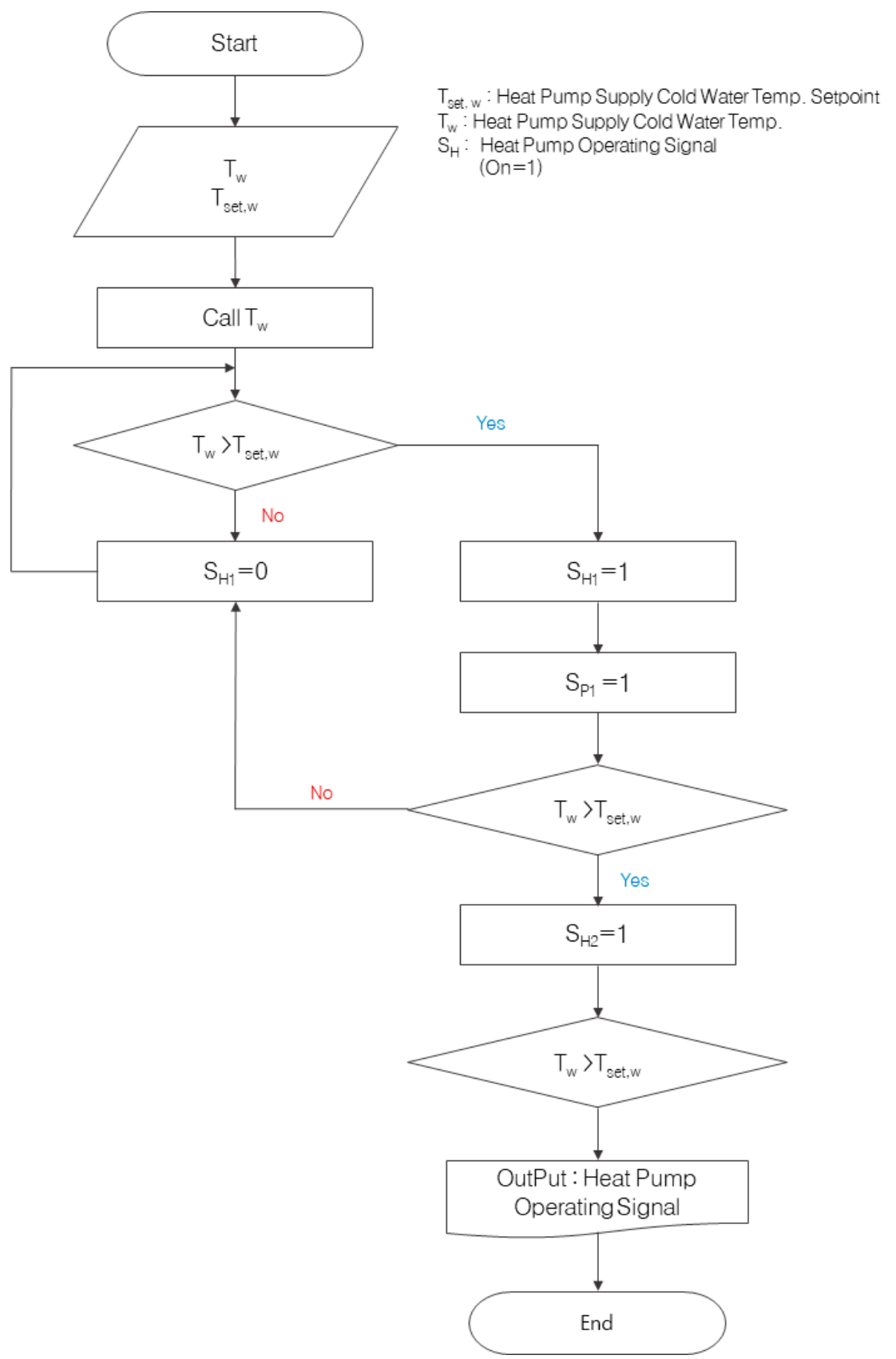

Figure 6. Algorithm of the existing operating number control method.

4.3. Proposed Sequential Operating Method of a Multi-Geothermal Heat Pump System using Variable Water Flow Rate Control

The flow rate of a variable water flow rate control method used to develop the multi-geothermal heat pump system operation was calculated using the following equations. The heat transfer rate was calculated from the flow rate and specific heat and temperature difference using Equation (9). The flow rate can be expressed as Equation (10):

$$
\begin{gathered}
q=m_{\text {source }} c_{p, \text { source }}\left(t_{\text {source }, i}-t_{\text {source }, 0}\right) \\
m_{\text {constant }}=\frac{q}{c_{p, \text { source }} \Delta t_{1}}
\end{gathered}
$$


When the load is the same, the relationship between the constant water flow control and variable water flow control is expressed as Equation (11). Therefore, the flow rate for the variable water flow control can be calculated using Equation (12) [18,19].

$$
\begin{gathered}
m_{\text {constant }} \Delta t_{1}=m_{\text {variable }} \Delta t_{2} \\
m_{\text {variable }}=m_{\text {constant }} \frac{\Delta t_{1}}{\Delta t_{2}}
\end{gathered}
$$

According to correlation analysis between the flow rate change and COP, the COP improves with decreasing flow rate. On the other hand, when controlling the variable water flow rate, the energy consumption of the heat pump increases more than the energy consumption of the circulation pump, and the COP decreases. In a previous study, the optimal water flow rate for the maximum performance of the geothermal heat pump system was derived from the results of COP analysis according to the water flow rate and temperature difference. When the temperature difference at the geothermal side was $5{ }^{\circ} \mathrm{C}$, the calculated water flow rate equaled the actual water flow rate, which represents the maximum performance [20]. Therefore, in this paper, the optimal temperature difference was utilized. To develop an operating method, this study utilized the variable water flow rate method to maintain a water flow rate that represents the maximum performance.

This study proposes the sequential operating method of the multi-geothermal heat pump system using variable water flow rate control and the COP prediction model. In addition, controls were set to maintain the optimal flow rate representing the high performance of the geothermal heat pump system. To control the water flow rate, the temperature difference of the geothermal side was set according to the optimal flow rate. When the geothermal system was operated, the temperature difference was calculated, and the water flow rate was controlled proportionally by a comparison with the optimal temperature difference. If the temperature difference was higher than the optimal temperature difference, the geothermal heat pump was set to operate sequentially. Figure 7 presents the proposed sequential operating method algorithm for operating the multi-geothermal heat pump system.

1. When the heat pump system is not operating

The geothermal heat pump is operated when the room temperature is higher than the set temperature $\left(T_{\text {room }}>T_{\text {set, }, \text { room }}\right)$. The temperature difference of one heat pump is then calculated. If the temperature difference is equal to the set temperature difference but cannot take charge of the room load, the next heat pump is operated. The current state is maintained if the temperature difference is higher than the set temperature difference $\left(\Delta T_{\text {source }}>T_{\text {set }}+d\right)$. Check for the occurrence of problems such as faults through the predicted COP at each operation.

\section{When the heat pump system is operating}

When the first heat pump operates, the heat pump stops operating if the room temperature is below the set temperature. The geothermal heat pump system is operated when the cooling load occurs. The water flow rate of the circulation pump is determined by the signal value $(0 \leq$ signal $\leq 1)$ by proportional control compared to the temperature difference set point. When the geothermal side temperature difference becomes higher than the set value $\left(\Delta T_{\text {source }}>T_{\text {set }}+d\right)$, the next heat pump is operated sequentially. Check for the occurrence of problems such as faults through the predicted COP at each operation. 


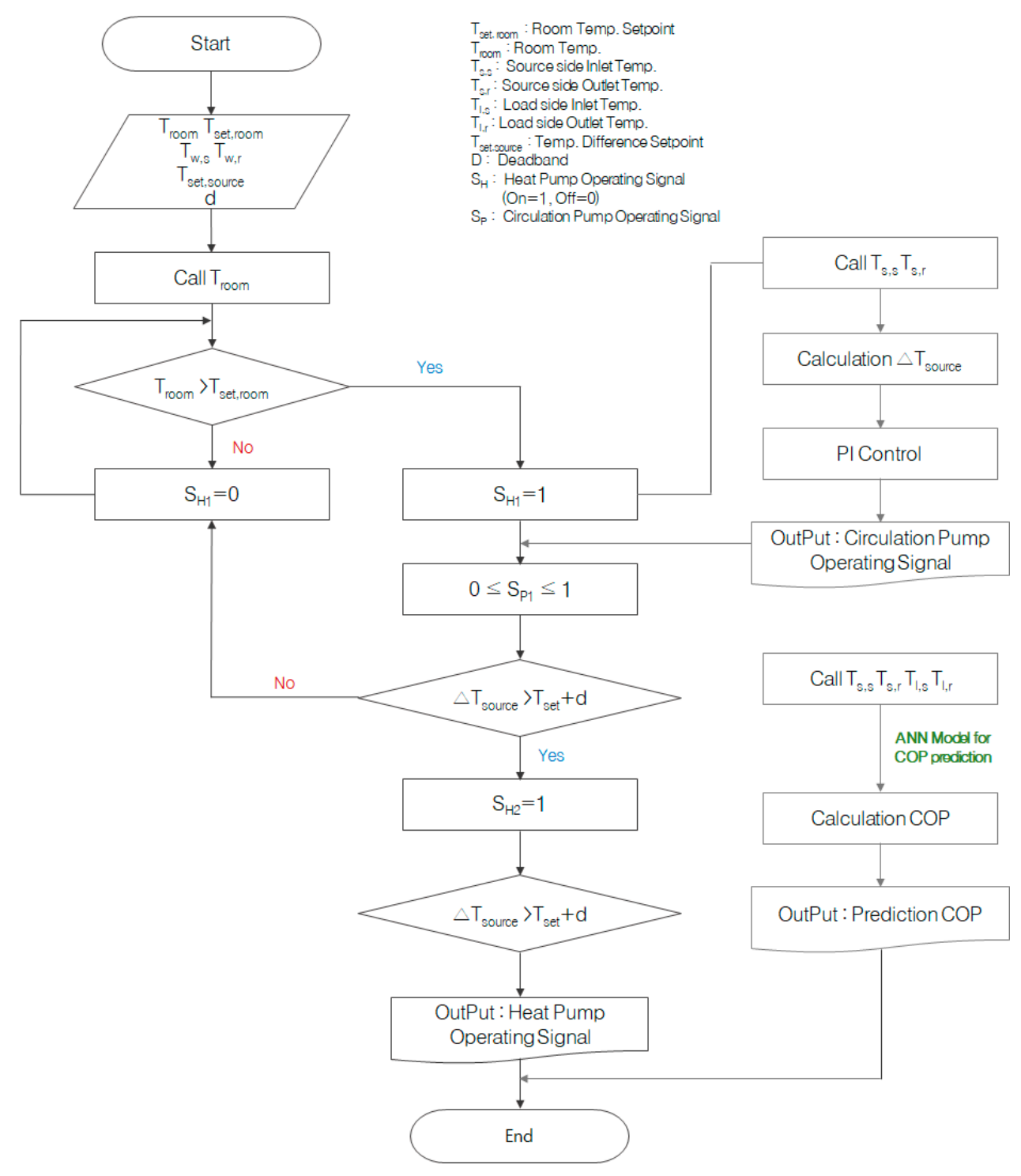

Figure 7. Algorithm of the proposed sequential operating method.

\section{Modeling Dynamic Simulation}

\subsection{Introduction of Dynamic Simulation}

This paper proposes the operating method of a multi-geothermal heat pump system using the flow rate control of the geothermal circulation pump according to the inlet and outlet temperature difference of geothermal circulation water and the condenser pressure of the geothermal heat pump system. The existing operating method of the target building and the proposed operating method were compared using simulations. The target building was modeled using the Google SketchUp program, and TRNbuild and Trnsys 17 were used to implement the mechanical system and provide detailed data of the target building. Through this, the simulation results were derived, and the proposed algorithm was evaluated.

The existing operating method of the multi-geothermal heat pump system of the target building utilizes the operating number control method and the constant water flow rate control method. The existing operating method was selected as Case 1. Case 2 was the proposed sequential operating method of the multi-geothermal heat pump system using variable water flow rate control. Types 16 (radiation processor), 33 (psychrometrics), and 69 (sky temperature calculation) were used in the simulation to compare the existing control method with the proposed control method. Types 
508a (cooling coil), 3c (fan), and 1669 (coil valve) were used for the heat pump and HVAC system implementation [21].

1. Operating number control method of a multi-geothermal heat pump system using constant water flow rate control (Case 1)

Figure 8 shows the simulation flow of the operating number control according to the set temperature using constant water flow rate control, which is the existing operating method of the target building. To implement the geothermal heat pump system, Type 927, which is a water-to-water type, was used as the heat pump and Type 557a, which is a vertical heat exchanger, was used as the geothermal heat exchanger. The geothermal circulation pump and cold water supply pump used Type $3 b$, which was a constant water flow rate pump. To control the set temperature of each geothermal heat pump, the set temperature of the heat pump was used as the controller input value. The controller used Type 911 (on/off controller). Figure 8 presents a simulation flow chart of the operating number control method.

2. Sequential operating method of a multi-geothermal heat pump system using variable water flow rate control (Case 2)

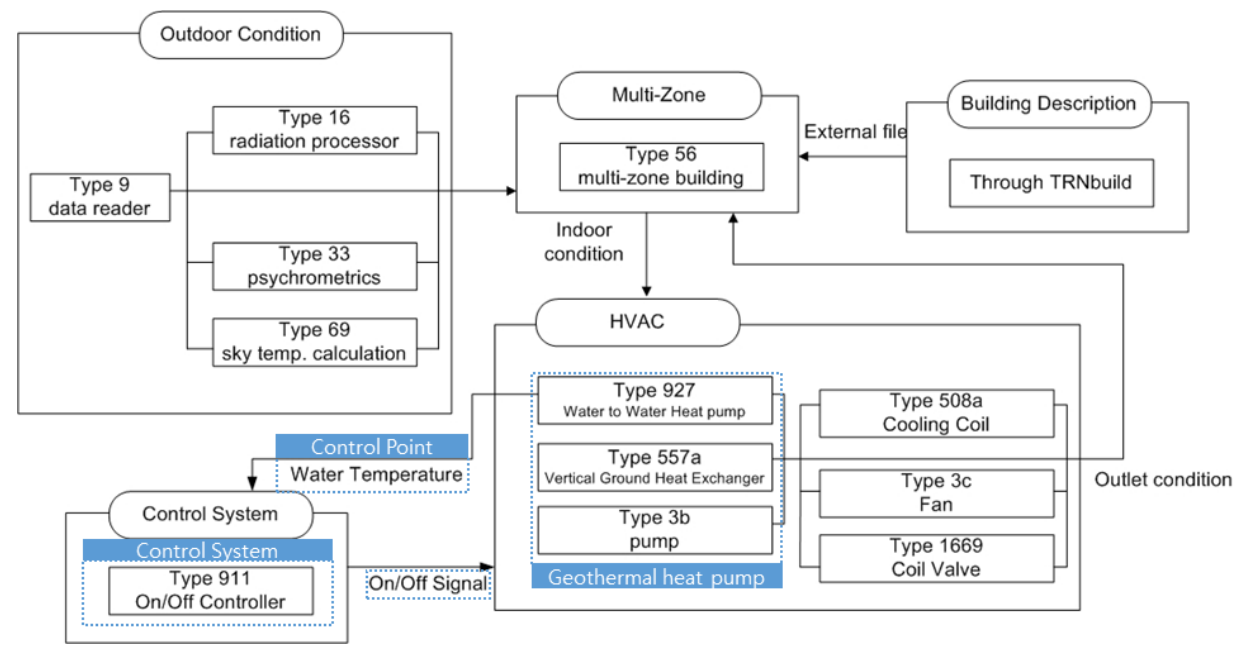

Figure 8. Simulation flow chart of the existing operating method (Case 1).

To implement the sequential operating method using variable water flow rate control, the inlet and outlet temperature difference of the geothermal circulation pump was utilized for control. The equation was used to calculate the temperature difference and reflect the room temperature, and Type 1669 (proportional controller) was used to control the flow rate from the difference in the geothermal side temperature. In the case of the circulation pump, Type 110 (variable speed pump), which can be controlled by the variable water flow rate, was implemented. Figure 9 presents the case of the sequential operating method using variable water flow rate control. 


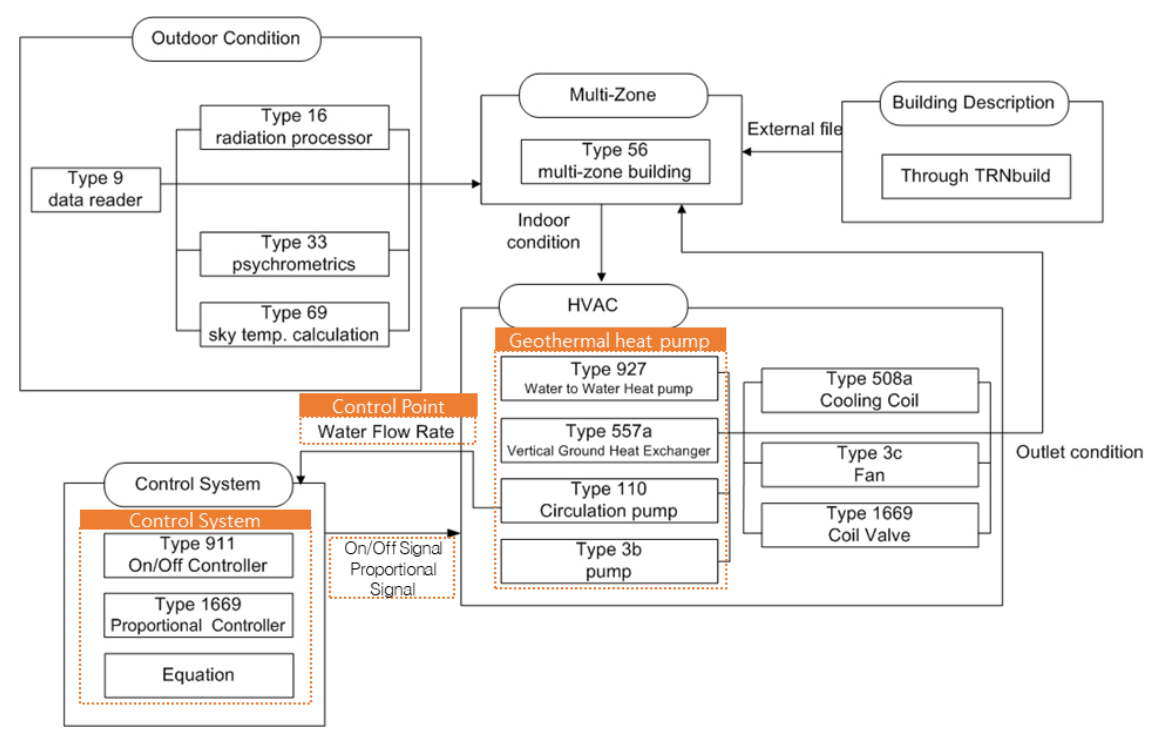

Figure 9. Simulation flow chart of the proposed operating method (Case 2).

\subsection{Results Analysis}

To analyze and apply the proposed operating method, the multi-geothermal heat pump system using variable water flow rate control was applied and compared with the existing operating method. The analytical items are the room temperature to determine if the room has been kept in a comfortable condition and the flow rate changes through variable water flow rate control. In addition, the energy consumption and COP of the geothermal heat pump system was analyzed to determine if the proposed operating method improves in terms of the energy and performance.

1. Analysis of the Indoor Thermal Environment

Thermal environment analyses of the existing geothermal heat pump system and proposed method were carried out. Figures 10 and 11 present the temperature change per case when the indoor set temperature was set to $24^{\circ} \mathrm{C}\left( \pm 0.5^{\circ} \mathrm{C}\right)$.

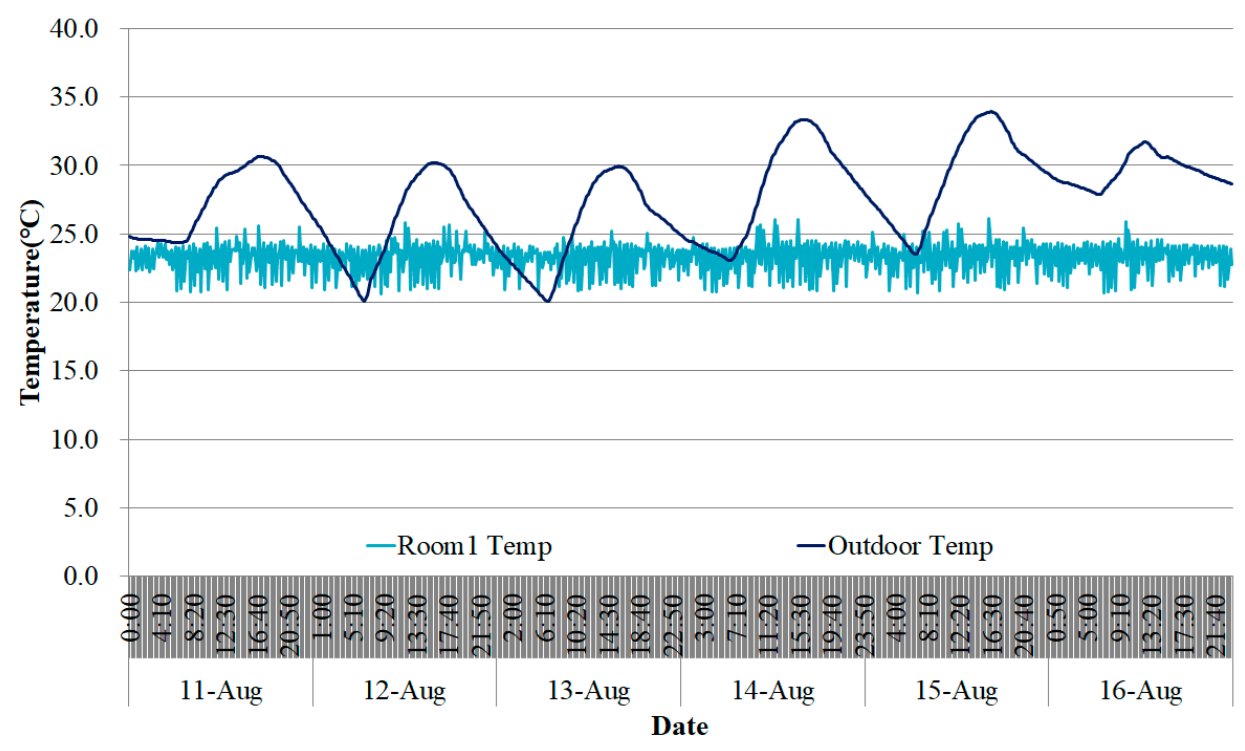

Figure 10. Room temperature (Case 1). 


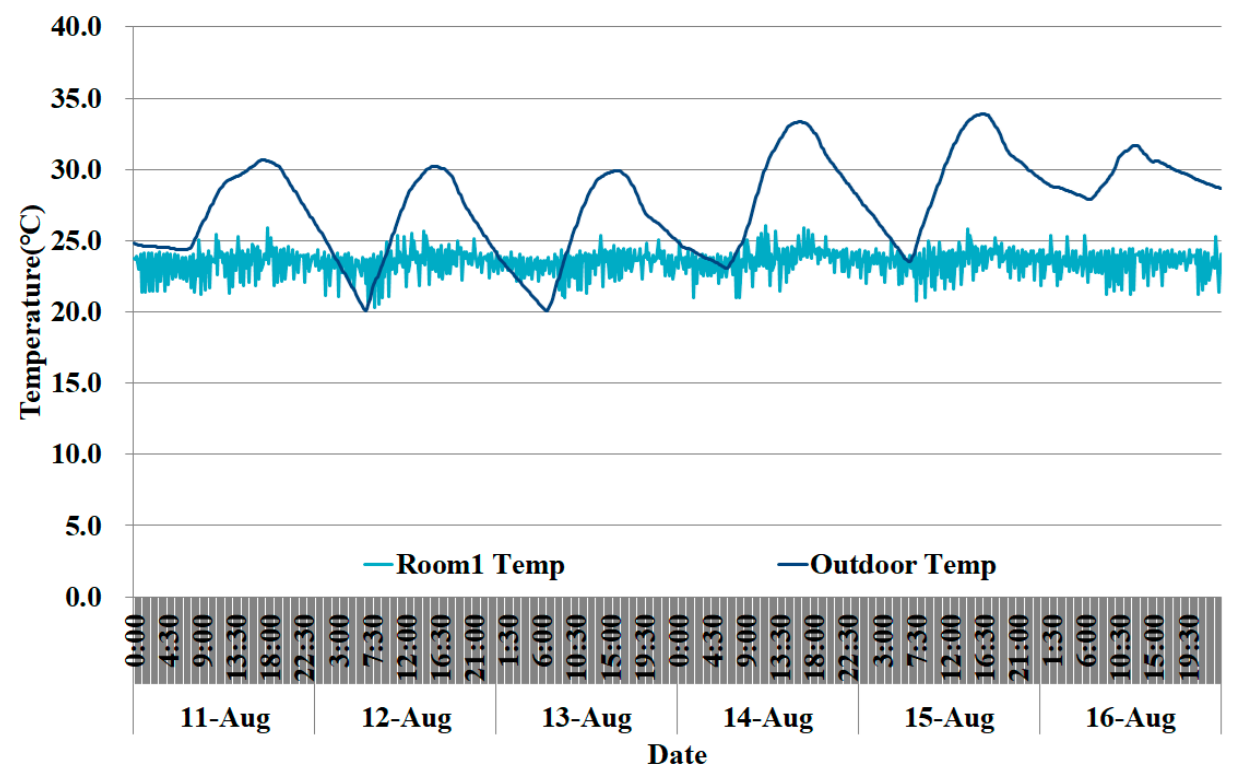

Figure 11. Room temperature (Case 2).

All spaces in the target building were controlled according to the indoor set temperature; Figures 10 and 11 show the temperature change in one representative room. The representative space was controllable within the set temperature deviation of the indoor space in both operating methods. The temperature deviation decreased when the proposed operating method was applied compared to the existing operating method of the target building. Therefore, the indoor thermal environment can be controlled stably using the proposed operating method.

2. Analysis of the geothermal circulation inlet and outlet temperature

Figures 12 and 13 show the results of the geothermal side inlet and outlet temperature analysis according to the operating method of the multi-geothermal heat pump system. The difference between the geothermal side inlet and outlet temperature is inversely proportional to the flow rate of the circulation pump.

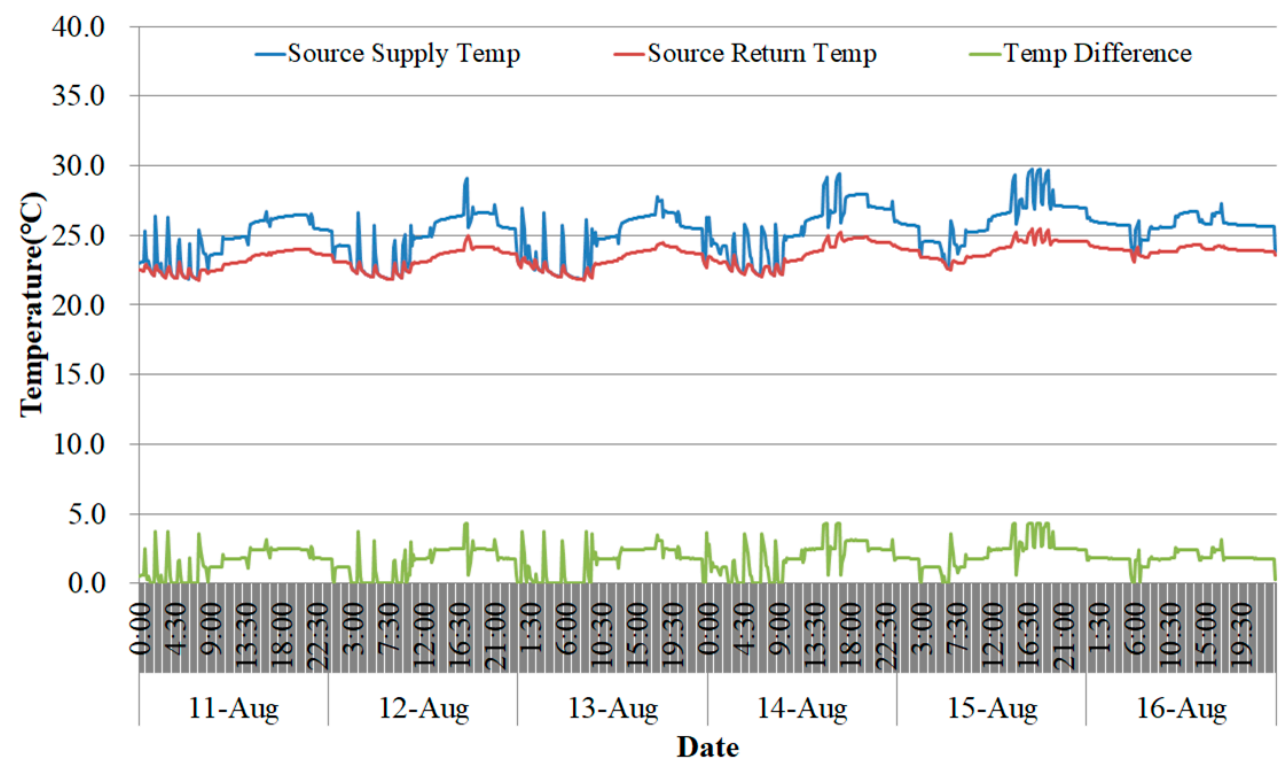

Figure 12. Geothermal water temperature (Case 1). 


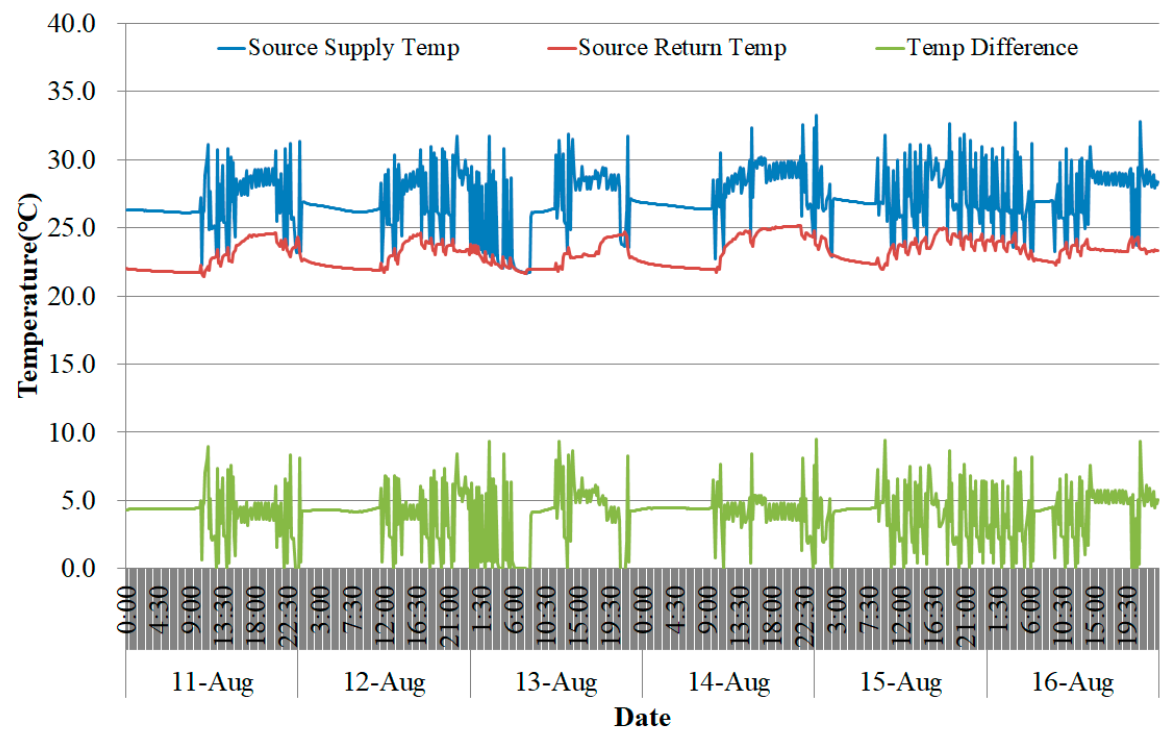

Figure 13. Geothermal water temperature (Case 2).

The change in the temperature difference depending on the load was not large because Case 1 supplies a constant flow rate regardless of the load. The average supply temperature of Case 1 was $25.2^{\circ} \mathrm{C}$; the average return temperature was $23.5^{\circ} \mathrm{C}$ and the average temperature difference was $1.7^{\circ} \mathrm{C}$. Case 2 controls the flow rate according to the optimal temperature difference of $5{ }^{\circ} \mathrm{C}\left( \pm 0.5^{\circ} \mathrm{C}\right)$ to operate the heat pump according to the flow rate that provides the highest efficiency. In Case 2, the average supply temperature was $27.1{ }^{\circ} \mathrm{C}$; the average return temperature was $23.1^{\circ} \mathrm{C}$ and the average temperature difference was $4{ }^{\circ} \mathrm{C}$. In addition, the flow rate was controlled according to the set temperature difference.

3. Water flow rate and energy consumption

The water flow rate of geothermal circulation water and the energy consumption were compared according to the operating method of the multi-geothermal heat pump system. Figure 14 presents the change in geothermal circulation water flow rate per case on the representative day. In Case 1, the flow rate was constant regardless of the load, whereas the flow rate changed depending on the load in Case 2. The maximum supply air flow of geothermal circulation water in Case 2 was $210 \mathrm{~m}^{3} / \mathrm{h}$, which is $29 \%$ lower than that in Case 1.

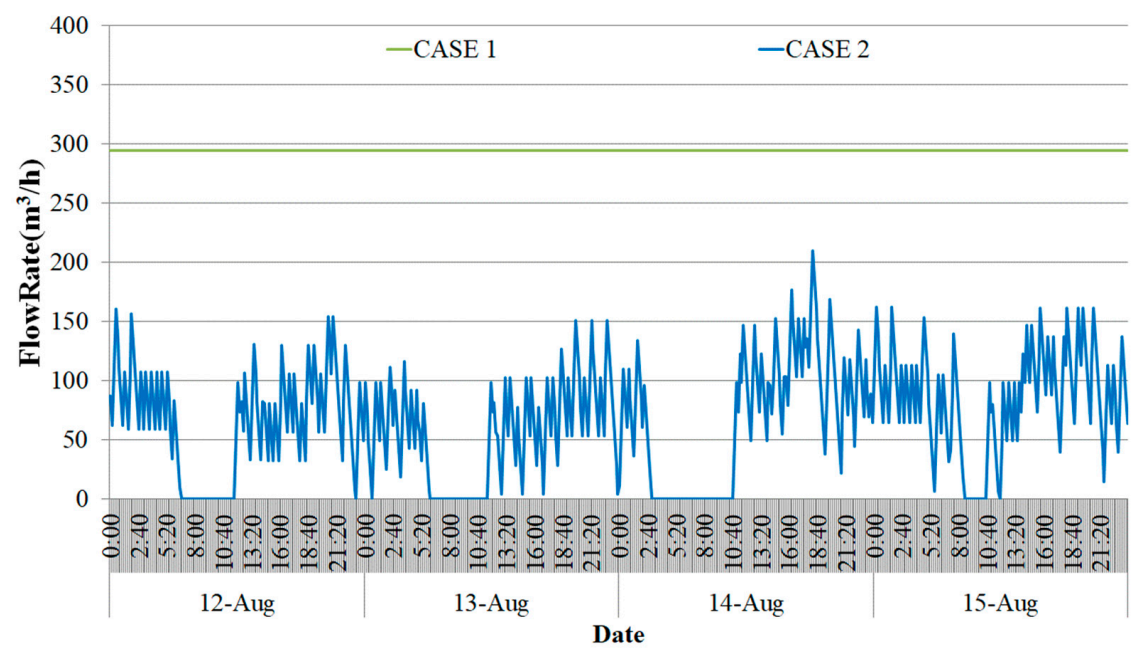

Figure 14. Water flow rate. 
Figure 15 shows the power consumption of the geothermal heat pump and circulation pump for each case. In Case 1, the power consumption of the heat pump and circulation pump was $1361 \mathrm{MW}$ and $340 \mathrm{MW}$, respectively. The power consumption of the heat pump was $1055 \mathrm{MW}$ and the power consumption of the circulation pump was $115 \mathrm{MW}$ in Case 2, which shows $23 \%$ and $66 \%$ energy reduction for the heat pump and circulation pump, respectively, compared to Case 1.

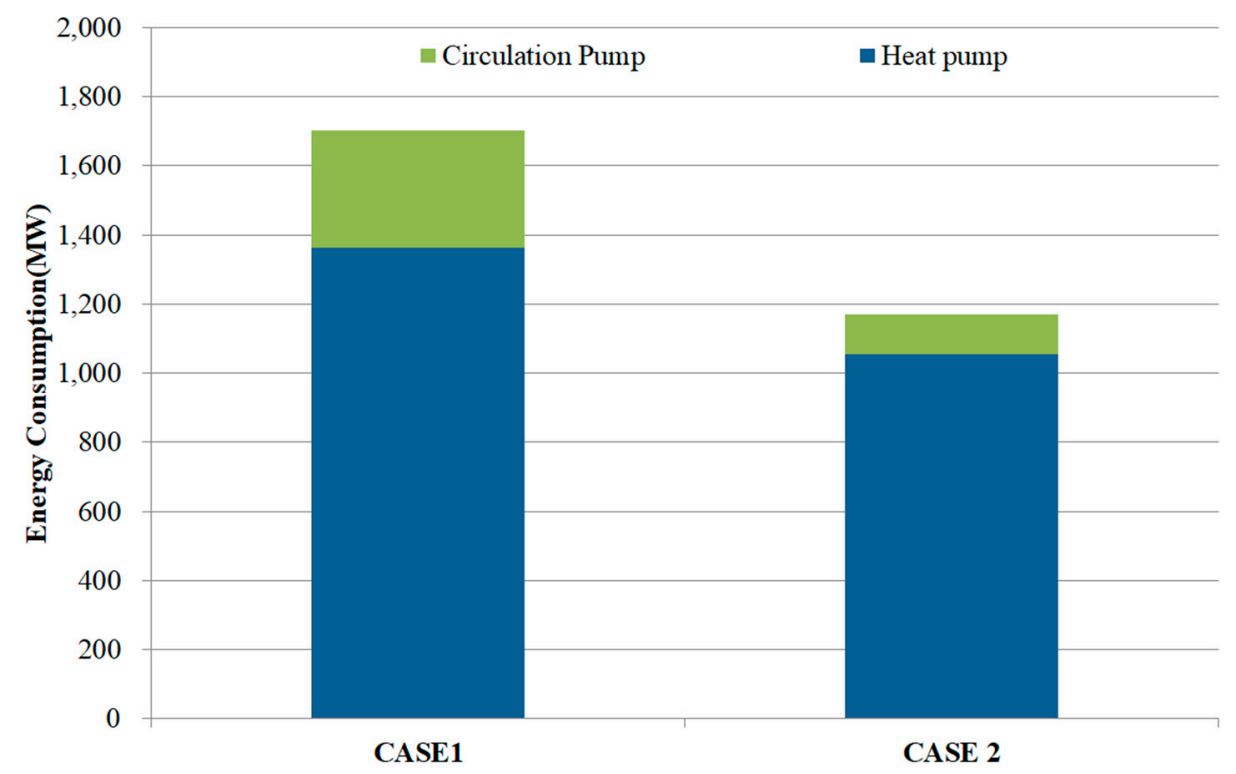

Figure 15. Energy consumption.

Energy savings can be achieved through the proposed multi-geothermal heat pump system operating method compared to the existing operating method that supplies circulating water continuously at a constant flow rate and operates the unnecessary geothermal circulation pump.

4. COP of the geothermal heat pump system

Figure 16 shows the results of COP analysis of the geothermal heat pump system according to the load. At the same load, the COP of the geothermal heat pump system showed that Case 2, which uses the variable water flow rate control for the operating heat pump system, was higher than that of Case 1 , which is the existing operating method. For Case 1, the average geothermal heat pump system COP was 3.07; the maximum COP of the system was 3.39, and the average system COP of Case 2 was 4.13. In Case 2, one heat pump exhibits the optimal performance and then the next heat pump is operated sequentially according to the variable water flow rate control; Case 2 performed better than Case 1 . Table 4 lists the detailed COP of the geothermal heat pump system per case. For Case 2, the maximum system COP increased by approximately 1.4 compared to Case 1. 


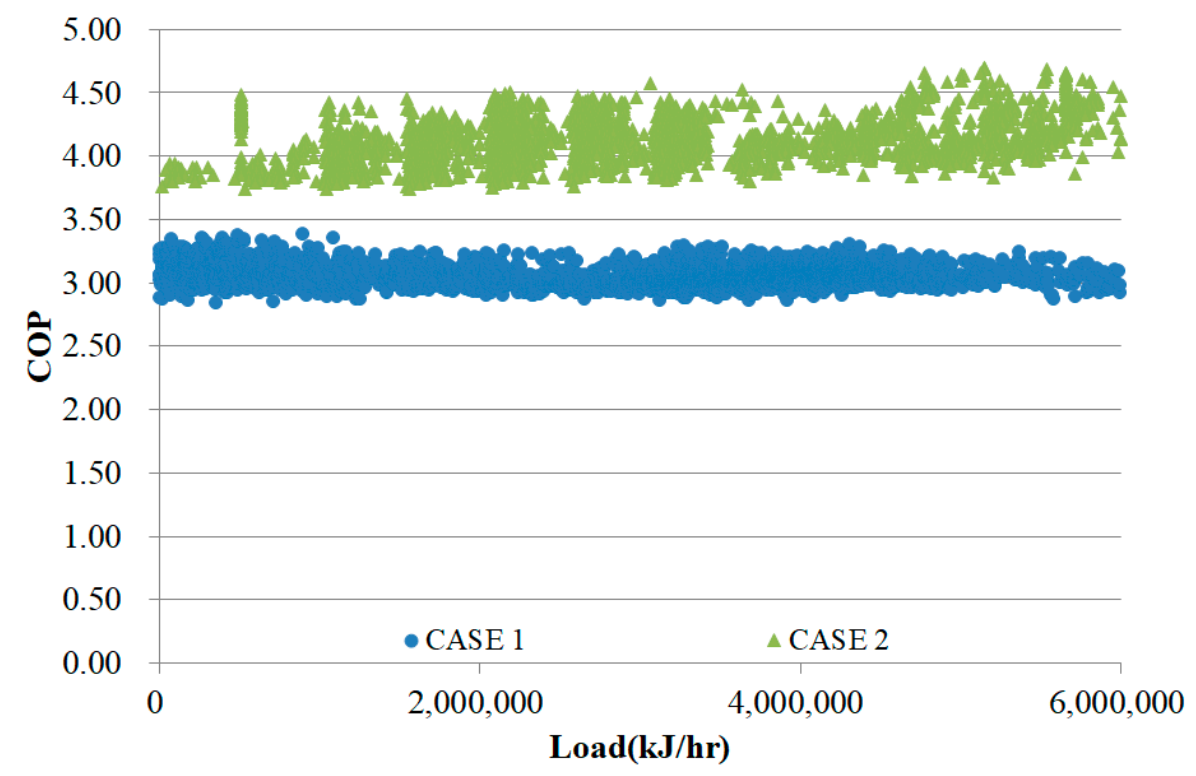

Figure 16. COP of the geothermal heat pump system.

\section{Conclusions}

The global energy growth trend has highlighted the importance of energy savings and efficient use, which has resulted in an increase in the installation and operation of geothermal heat pump systems. After the application of a geothermal heat pump system, the problem of efficiency deterioration due to inefficient operation frequently occurs. The aim of this study was to develop and verify an operating method for energy savings and performance improvement of multi-geothermal systems. The operating method of a multi-geothermal heat pump system using a variable water flow rate control method and COP prediction model were developed. The developed operating method can improve the performance of the entire system as well as the energy savings of the circulation pump. The results of this study are as follows:

1. The lack of equipment and monitoring systems in the field makes it difficult to verify the performance in real time. The COP prediction model using an artificial neural network was developed. The developed prediction model was validated by statistical analysis. Predictive models were applied to geothermal system operation algorithms to identify problems, such as poor performance.

2. To operate the geothermal heat pump system more efficiently than the existing operating method, the COP prediction model using an ANN and the variable water flow control method of circulation pump were applied to develop an operating method. The flow rate was controlled proportionally through the geothermal temperature difference in the proposed operating method. If the setting value is over, the geothermal heat pump operates in sequence. The COP prediction model enables real-time performance prediction during system operation.

3. The proposed multi-geothermal heat pump system operation was verified for an indoor thermal environment, circulating water flow rate, energy consumption, and geothermal heat pump system COP. The proposed operating method can control the indoor heat environment stably and the circulating water supply flow rate is reduced by up to $29 \%$ compared to the existing operation method. Geothermal heat pumps can save approximately $23 \%$ and $66 \%$ energy and circulating pumps, respectively. Thus, the system COP, including the power consumption of the circulation pump, is improved.

The developed COP prediction model using the ANN can be used for real-time performance checks, which can be used for fault diagnosis of geothermal heat pump systems. The operation plan of the developed multi-geothermal heat pump system can be utilized for improving system performance 
and efficient operation. Subsequent studies will be carried out to develop a performance prediction model using various models to improve the accuracy of the performance prediction model, and to analyze the economic effect of improving the operation plan.

Author Contributions: All authors contributed to this work. J.-H.S. investigated and wrote the original draft. Y.-H.C. did project administration and supervised. Y.-I.K. gave conceptual advice.

Funding: This research was funded by a grant (19CTAP-C143443-02) from Technology Advancement Research Program funded by the Ministry of Land, Infrastructure and Transport of the Korean Government.

Acknowledgments: This study was supported by a grant (19CTAP-C143443-02) from Technology Advancement Research Program funded by the Ministry of Land, Infrastructure and Transport of the Korean Government.

Conflicts of Interest: The authors declare no conflict of interest.

\section{Nomenclature}

$\begin{array}{ll}w & \text { Weights } \\ \mathrm{x} & \text { Input value } \\ b & \text { Bias value } \\ \alpha & \text { Learning rate } \\ x_{\text {actual }} & \text { Measured value } \\ x_{\text {calculate }} & \text { Calculated value } \\ q & \text { Heat transfer rate, } \mathrm{kW} \\ \Delta t & \text { Temperature difference, }{ }^{\circ} \mathrm{C} \\ m_{\text {constant }} & \text { Water flow rate at constant flow rate control } \\ m_{\text {variable }} & \text { Water flow rate at variable flow rate control }\end{array}$

\section{References}

1. Granryd, E. Analytical expressions for optimum flow rates in evaporators and condensers of heat pumping systems. Int. J. Refrig. 2010, 33, 1211-1220. [CrossRef]

2. Song, S. An Experimental Study on Variable-Speed Control of an Ground-Water Circulation Pump for a Ground Source Multi-Heat Pump System. Korean J. Air Cond. Refrig. Eng. 2013, 25, 443-449.

3. Montagud, C.; Corberán, J.M.; Montero, Á. In situ optimization methodology for the water circulation pumps frequency of ground source heat pump systems. Energy Build. 2014, 68, 42-53. [CrossRef]

4. Cerverar-Vazquez, J.; Montagud, C.; Corberán, J.M. In situ optimization methodology for the water circulation pumps frequency of ground source heat pump systems: Analysis for multistage heat pump units. Energy Build. 2015, 88, 238-247. [CrossRef]

5. Sarbu, I. Performance Evaluation of Radiator and Radiant Floor Heating Systems for an Office Room Connected to a Ground-Coupled Heat Pump. Energies 2016, 9, 228. [CrossRef]

6. Vakiloroaya, V. Energy-efficient HVAC systems: Simulation empirical modelling and gradient optimization. Autom. Constr. 2013, 31, 176-185. [CrossRef]

7. Girard, A. Higher ground source heat pump COP in a residential building through the use of solar thermal collectors. Renew. Energy 2015, 80, 26-39. [CrossRef]

8. Liu, X. Performance analysis of a multi-functional heat pump system in cooling mode. Appl. Therm. Eng. 2013, 59, 253-266. [CrossRef]

9. Zogou, O. Optimization of thermal performance of a building with ground source heat pump system. Energy Convers. Manag. 2007, 48, 2853-2863. [CrossRef]

10. Jung, Y. A Study on the Geothermal Heat Pump System Performance Analysis According to Water Flow Rate Control of the Geothermal Water Circulation Pump. J. Korean Sol. Energy Soc. 2014, 34, 103-109. [CrossRef]

11. Ozgener, O. Experimental investigation of the performance of a solar-assisted ground-source heat pump system for greenhouse heating. Int. J. Energy Res. 2004, 29, 217-231. [CrossRef]

12. Mocanu, E.; Nguyen, P.H.; Gibescu, M.; Kling, W.L. Deep learning for estimating building energy consumption. Sustain. Energy 2016, 6, 91-99. [CrossRef] 
13. Buratti, C.; Vergoni, M.; Palladino, D. Thermal comfort evaluation within non-residential environments: Development of Artificial Neural Network by using the adaptive. Energy Procedia 2015, 78, 2875-2880. [CrossRef]

14. Kumar, R.; Aggarwal, R.K.; Sharma, J.D. Energy analysis of a building using artificial neural network: A review. Energy Build. 2013, 65, 352-358. [CrossRef]

15. Moon, J.W.; Kim, J.J. ANN-based thermal control models for residential buildings. Build. Environ. 2010, 45, 1612-1625. [CrossRef]

16. Sun, W.; Hu, P.; Lei, F.; Zhu, N.; Jiang, Z. Case study of performance evaluation of ground source heat pump system based on ANN and ANFIS models. Appl. Therm. Eng. 2015, 87, 586-594. [CrossRef]

17. Esen, H.; Inalli, M.; Sengur, A.; Esen, M. Artificial neural networks and adaptive neuro-fuzzy assessments for ground-coupled heat pump system. Energy Build. 2008, 40, 1074-1083. [CrossRef]

18. Haberl, J.S.; Claridge, D.E.; Culp, C. ASHRAE's GUIDELINE 14-2002 for Measurement of Energy and Demand Savings: How to Determine What Was Really Saved by the Retrofit; Energy Systems Laboratory, Texas A \& M University: College Station, TX, USA, 2005.

19. American Society of Heating, Refrigerating and Air-Conditioning Engineers. ASHRAE Handbook-Fundamentals; American Society of Heating, Refrigerating and Air-Conditioning Engineers, Inc.: Atlanta, GA, USA, 2009.

20. Shin, J.H.; Cho, Y.H. Development of a Variable Water Flow Rate Control Method for the Circulation Pump in a Geothermal Heat Pump System. Energies 2018, 11, 718. [CrossRef]

21. University of Wisconsin Madison. Trnsys 17 Reference Manual; University of Wisconsin Madison: Madison, WI, USA, 2010.

(C) 2019 by the authors. Licensee MDPI, Basel, Switzerland. This article is an open access article distributed under the terms and conditions of the Creative Commons Attribution (CC BY) license (http://creativecommons.org/licenses/by/4.0/). 